\title{
Analysis on Teaching of Creation Course
}

\author{
Li Xie* \\ College of Mechanical Engineering \\ Dongguan University of Technology \\ Dongguan, China \\ shirley115_1@163.com \\ Zixuan Liu \\ College of Mechanical Engineering \\ Dongguan University of Technology \\ Dongguan, China
}

\author{
Weiben $\mathrm{Xu}$ \\ College of Mechanical Engineering \\ Dongguan University of Technology \\ Dongguan, China
}

\begin{abstract}
Creation is a course of industrial design. In this paper, importance of this course was analyzed. Some suggestions on effective and reasonable connection of Creation with other curriculums were proposed. Research conclusions could provide beneficial references to future teaching of Creation.
\end{abstract}

Keywords-Creation; teaching; industrial design

With the opening and transition of the design education system, education of the industrial design will encounter many problems in the long-run development. Many universities, including some comprehensive universities of non-art category, have offered similar courses successively. However, most of them only tell students what is industrial design, but fail to inform students what to do, how to do, how to think and how to make innovations. It is an urgent task to implement more effective teaching activities in education of product design. However, Creation which places innovation in the first place is undervalued. In this paper, importance of Creation was analyzed and suggestions on effective and reasonable connection of Creation with other curriculums were proposed.

Creation is set based on the importance of creation in design. It is a science that studies people's creativity and invention activities in all fields (e.g. science, technology, management and art) as well as explorations of corresponding processes, characteristics, laws and methods. [1]It was born in the first half of the 20th century and achieved an extremely rapid development in foreign countries. But it was until the end of 20th century that the Creation was introduced into Mainland China. Modern art design technologies developed rapidly and the disciplines related with design are increasing day by day. How to apply theory and methods of creation into art design is a field of current art design. In the following text, some analyses were carried out with considerations to the close relationship between the creation theory and design innovation.

\section{OVERVIEW ON INNOVATION AND INNOVATIVE THINKING}

In creation, innovative ability is defined the top ability of creativity. Creation was originated to Latin and it was evolved

\author{
Guohong $\mathrm{Wu}$ \\ Dongguan Hengli Mould Technology Development Limited \\ Company \\ Dongguan, China
}

from updating, creating new things and change, which the source impetus to facilitate social development and continuous progress of human. Based on the art design innovation, creation is the design method that combines the relative innovative thinking and innovative techniques with the traditional art design methods. It is not only the exploration of modern art design methodology, but also the perfection of existing design method system. Thinking is a kind of very complicated psychological phenomenon and possesses multiple important attributes or properties. Kohler Sinek, an American psychologist, believed that "creative thinking refers to the discovery or invention of a new method to process some event or express the thinking process of something."

\section{FORMS OF INNOVATIVE THINKING IN ART DESIGN}

In creation, innovative ability is defined the top ability of creativity. Creation was originated to Latin and it was evolved from updating, creating new things and change, which the source impetus to facilitate social development and continuous progress of human. Based on the art design innovation, creation is the design method that combines the relative innovative thinking and innovative techniques with the traditional art design methods. It is not only the exploration of modern art design methodology, but also the perfection of existing design method system. Thinking is a kind of very complicated psychological phenomenon and possesses multiple important attributes or properties. Kohler Sinek, an American psychologist, believed that "creative thinking refers to the discovery or invention of a new method to process some event or express the thinking process of something." Creative thinking in art design generally has two basic forms. One is the divergent thinking and the other one is the convergent thinking. Creative thinking is the organic combination of logical thinking, imaginable thinking, divergent thinking and convergent thinking.

In this paper, the divergent thinking and convergent thinking are not explained. However, they supplement each other in the creative thinking and form a dialectical unity. The thinking process in any creative activity has to experience from the divergent thinking to the convergent thinking and then to the divergent thinking, and finally to the convergent thinking. 
This cycle has to be repeated over and over again in order to solve one problem. The art design covers all four forms of thinking, because it is a strong interdisciplinary course. An excellent art design is the outcome of mutual action and mutual promotion of creative thinking in the design.

\section{ROLE OF CREATIVE THINKING IN ART DESIGN}

Creative thinking is an important concept in art design and plays an important role in different development stages of art design. I not only can increase the art design efficiency, but also can enhance the art design effect.

Firstly, creative thinking is conducive to increase the conceptual design efficiency the concept of problem solving ability. In the art design field, conceptual design determines the design direction and it is the most creative part in art design. Reasonable use of creative thinking is able to improve quality and time efficiency of conceptual design. Secondly, creative thinking could develop the efficiency of a design team to the maximum extent. Nowadays, many art designs are accomplished by teamwork. In the design team, it is advocated that creative thinking can increase the team efficiency greatly. Finally, creative thinking is conducive to design optimization. [2]Art design is a process of creating a work from nothing and is a process of continuous optimization of design schemes. The same work may get different design schemes by using different creative thinking principles.

\section{CURRENT SITUATIONS OF CREATION IN UNIVERSITIES}

Although creation has achieved great progresses in discipline construction, it is still weakly connected with other disciplines. The key design curriculum in most universities still uses three major components dominated by the Bauhaus teaching system as the teaching basis of the design major. Particularly, students of industrial design in comprehensive universities present relatively weaker cognitive basis. They are neither familiar with the traditional perceptual art creations (e.g.pencil sketch and colors) nor good at composition courses.

Many teachers deemed that students of science and engineering majors have strong logical thinking, so they are good at composition courses. However, they are difficult to be "creative", "effective" and "innovative" in practices in relative to practical problem solving of "observing all rules and regulations". What they are neglected is the creative consciousness of students of the design major. Sometimes, students of science and engineering majors view "imaging" and "unconstrained thinking" as making troubles out of nothing, but they neglect that some ideas are inspired from the important significance of imaging.

\section{RELATIONSHIPS OF CREATION WITH OTHER DESIGN CURRICULUM STUDENTS}

It has been proved in Section 4 that Creation is the basis of many design curriculums. It is the thinking pioneer of other design curriculums and even fundamental curriculums. If students only engage in creation after they have learned some design curriculums, their design judgment basically has been fixed. Such foundation is extremely important. In teaching activities, teachers shall emphasize on how to teach students to think rather than the necessary fruits after thinking. Fruits cannot represent the thinking ability. Therefore, creation can offer great guidance to students in problem thinking mode and problem solving method during construction of the teaching system. [3]Just as an old Chinese saying goes that "Give a man a fish and you feed him for a day. Teach a man to fish and you feed him for a lifetime". The information that has to be transmitted is how to develop, excite and train students' creativity, innovative thinking and ability of flexibility use. This is the appeal of education.

\section{TEACHING SUGgESTIONS TO CREATION}

If a course cannot exist in the whole teaching system appropriately, it will fail to develop the maximum significance no matter how important it is.

Firstly, attentions shall be paid to curriculum setting of Creation, including the creation course and basis of all professional courses. It is the guide nice direction and baton.

Secondly, the arrangement of creation and other curriculums shall consider its role of an important basis. It shall be offered to low grades to train students' habit of innovative thinking as early as possible.

Thirdly, creation curriculum shall be constructed by keeping pace with the times rather than focusing on the creation alone. Students' status, social status and enterprise' status shall be considered in the teaching system. [4]The primary goal is to train talents desired by the society and enterprises.

The primary goal is to train talents desired by the society and enterprises.

\section{CONCLUSIONS}

In this paper, some suggestion for the Creationare proposed based on teaching experience and the relevant curriculum lysis. Research conclusions can provide references for future teaching of the Creation.

\section{ACKNOWLEDGMENT}

The study was supported by the Project of Education of Dongguan University of Technology (Project Name: Video open class, Design thinking and expression ), the Project of Education of Dongguan University of Technology (Project Name: Results-oriented teaching method in the industrial design major of the curriculum practice in the research design basis) the Project of College Students' innovation and entrepreneurship training of Dongguan University of Technology (Project Name: Research on smart home product design based on audio-visual equipment, NO.201711819080), the Project of Department of Education of Guangdong Province (Project Name: Research of Witkey-Based Teaching Pattern of Innovative and Entrepreneurial Practice for Mechanical Specialty), the Project of Education of Dongguan University of Technology (Project Name: Mechanical Drawing Teaching Team), and the Industrial-academic-research cooperation demonstration base of DGUT-HengLi Town. 


\section{REFERENCES}

[1] Jiaoping Xie.Kang Xu.Theory of creatology teaching for students to think about the impact of the [J].The invention and innovation: comprehensive edition, 2008

[2] Rehong Fang.Art design classroom teaching creative thinking development research [J].Shantou university, 2009
[3] GongJiang Jian.Creative study development at home and abroad comparative study [D].China university of science and technology, 2012

[4] Yan Song.Ideological and political education innovation in colleges and universities entrepreneurship education and research [D].Northeast normal university, 2 